\title{
A GLOBAL CHARACTERISTIC OF G-LIMIT OPERATORS FOR QUASILINEAR POTENTIAL ELLIPTIC SYSTEMS ${ }^{1}$
}

\section{U. RAITUMS}

Institute of Mathematics and Computer Science University of Latvia

Rainis boulevard 29, LV-1459 Riga, Latvia

E-mail: uldis.raitums@mii.lu.lv

Received September 24, 2002

\section{ABSTRACT}

The paper considers a family of quasilinear potential elliptic systems and uses the fact that all G-limit operators for this family can be characterized by means of gradients of convex functions $F$ (locally with respect to the spatial co-ordinates). It is shown that all these functions $F$ must satisfy an inequality expressed in terms of functions $F$ and their conjugate functions.

Key words: elliptic systems, convex functions, $G$-limit operators.

\section{INTRODUCTION}

In this paper, we give a characteristic of G-limit operators for simple quasilinear potential elliptic systems of the kind

$$
\begin{aligned}
& \operatorname{div}\left[\sum_{s=1}^{N} \sigma_{s}(x) F_{s}^{\prime}(\nabla \bar{u}(x)+g(x))-f(x)\right]=0 \text { in } \Omega, \\
& \bar{u}=\left(u_{1}, \ldots, u_{m}\right) \in H_{0}^{1}\left(\Omega ; \mathbf{R}^{m}\right),
\end{aligned}
$$

depending on the functional parameter $\sigma$

$$
\begin{aligned}
& \sigma \in S=\left\{\sigma \in L_{\infty}\left(\mathbf{R}^{n} ; \mathbf{R}^{N}\right) \mid \sigma=\left(\sigma_{1}, \ldots, \sigma_{N}\right)\right. \\
& \sigma_{j}(x)=0 \text { or } 1, j=1, \ldots, N \\
& \left.\sigma_{1}(x)+\cdots+\sigma_{N}(x)=1 \text { a.e. } x \in \mathbf{R}^{n}\right\}
\end{aligned}
$$

Here $F_{s}, s=1, \ldots, N$, are given strictly convex smooth functions with quadratic growth, $F_{s}^{\prime}(\cdot)$ is the gradient of $F_{s}(\cdot), s=1, \ldots, N$.

\footnotetext{
${ }^{1}$ This research was partially supported by the Latvian Council of Sciences, Grant No. 01.0441 .
} 
It is known, see for instance, Raitums [3], that all $G$-limit operators for the family (1.1) can be fully characterized by the set $\mathcal{A}$ of functions

$$
\mathcal{A}=\left\{F_{\sigma} \in C^{1}\left(\mathbf{R}^{n m}\right) \mid \sigma \in S\right\}
$$

where for a chosen $\sigma \in S$

$$
F_{\sigma}(z)=\inf _{v \in H^{\#}} \int_{K} \sum_{s=1}^{N} \sigma_{s}(x) F_{s}(v(x)+z) d x, \quad \forall z \in \mathbf{R}^{n m} .
$$

Here $K \subset \mathbf{R}^{n}$ is the unit cube, $K=(0,1)^{n}$, and

$$
H^{\#}=\left\{v \in L_{2}\left(K ; \mathbf{R}^{n m}\right) \mid v=\nabla \bar{u}, \bar{u} \in H_{l o c}^{1}\left(\mathbf{R}^{n}, \mathbf{R}^{m}\right), \bar{u} \text { is } K \text { - periodic }\right\} \text {. }
$$

One of the main features of the nonlinear (the functions $F_{s}^{\prime}(\cdot)$ are not affine) case is that the properties of $F_{\sigma}(\cdot)$ at a point $z$ depend on the behaviour of $F_{s}$ on the whole $\mathbf{R}^{n m}$, i.e. these properties are not local.

We are interested in the question of the existence of a larger set $\hat{\mathcal{A}} \subset$ $C^{1}\left(\mathbf{R}^{n m}\right)$ of strictly convex functions $\hat{F}$ such that if for some $z^{\prime} \in \mathbf{R}^{n m}$

$$
\hat{F}^{\prime}\left(z^{\prime}\right)=z^{\prime \prime}
$$

then there exists a sequence $\left\{F_{\sigma^{k}}\right\} \subset \mathcal{A}$ such that

$$
F_{\sigma^{k}}^{\prime}\left(z^{\prime}\right) \rightarrow z^{\prime \prime} \text { as } k \rightarrow \infty
$$

If such a set $\hat{\mathcal{A}}$ (with some additional properties) exists then by standard methods of the theory of G-convergence and monotone operators one can easy show that for every solution $\bar{u}^{0}$ of the system

$$
\begin{gathered}
\operatorname{div}\left(\sum_{s=1}^{s_{0}} \chi_{\Omega_{s}}(x) \hat{F}_{s}^{\prime}(\nabla \bar{u}(x)+g(x))-f(x)\right)=0 \text { in } \Omega \\
\bar{u} \in H_{0}^{1}\left(\Omega ; \mathbf{R}^{m}\right)
\end{gathered}
$$

there exists a sequence $\left\{\sigma^{k}\right\} \subset S$ such that the sequence $\left\{\bar{u}^{k}\right\}$ of solutions of the system (1.1) with $\sigma=\sigma^{k}, k=1,2, \ldots$, respectively converges weakly in $H_{0}^{1}\left(\Omega ; \mathbf{R}^{m}\right)$ to $\bar{u}^{0}$ as $k \rightarrow \infty$. Here $\left\{\Omega_{s}\right\}$ is a partition of $\Omega$ by means of pairwise disjoint measurable sets $\Omega_{s}, \chi_{\Omega_{s}}$ is the characteristic function of $\Omega_{s}$ and $\hat{F}_{s} \in \hat{\mathcal{A}}, s=1, \ldots, s_{0}$.

In this sense the passage from $\left\{F_{1} ; \ldots ; F_{N}\right\}$ to $\mathcal{A}$ and further to $\hat{\mathcal{A}}$ preserves the weak closure of the set of all feasible solutions of the family (1.1).

In what follows (Section 3) we shall show that if the functions $F_{s}, s=$ $1, \ldots, N$, satisfy some hypotheses (see Section 2 ) then there exists such a set $\hat{\mathcal{A}}$ and its main functional characteristic is

$$
\hat{F}\left(z^{\prime}\right)+\hat{F}^{*}\left(z^{\prime \prime}\right) \geq Q \mathcal{F}\left(z^{\prime}, z^{\prime \prime}\right) \quad \forall z^{\prime}, z^{\prime \prime} \in \mathbf{R}^{n m},
$$


where $Q \mathcal{F}$ is some (curl, div) ${ }^{m}$ - quasiconvex function and by $\hat{F}^{*}$ is denoted the conjugate to $\hat{F}$ function.

\section{PRELIMINARIES}

Let $n \geq 2, m \geq 1, N \geq 2$ be integers and let the functions $F_{s}: \mathbf{R}^{n m} \rightarrow$ $\mathbf{R}, s=1, \ldots, N$, satisfy the following hypotheses.

H1. $F_{s}, s=1, \ldots, N$, belong to $C^{1}\left(\mathbf{R}^{n m}\right)$ and are strictly convex.

H2. There exist positive constants $\nu, \mu$ such that for all $z, \xi \in \mathbf{R}^{n m}$

$$
\begin{aligned}
& \left|F_{s}^{\prime}(z)-F_{s}^{\prime}(\xi)\right| \leq \mu|z-\xi|, \\
& \left\langle F_{s}^{\prime}(z+\xi)-F_{s}^{\prime}(z), \quad \xi\right\rangle \geq \nu|\xi|^{2}, \quad s=1, \ldots, N .
\end{aligned}
$$

H3. $F_{s}(0)=0, F_{s}^{\prime}(0)=0, s=1, \ldots, N$.

For a given function $F: \mathbf{R}^{n m} \rightarrow \mathbf{R}$ by $F^{*}$ we shall denote its conjugate function, i.e.

$$
F^{*}\left(z^{\prime \prime}\right)=\sup _{z^{\prime} \in \mathbf{R}^{n m}}\left[\left\langle z^{\prime}, z^{\prime \prime}\right\rangle-F\left(z^{\prime}\right)\right]
$$

From H1 - H3 it follows immediately that $F_{s}$ and $F_{s}^{*}$ are nonnegative and that the conjugate functions $F_{s}^{*}$ have analogous to $\mathbf{H 1}-\mathbf{H 3}$ properties (with different constants $\nu^{\prime}, \mu^{\prime}$ instead of $\left.\nu, \mu\right)$.

Let $K \subset \mathbf{R}^{n}$ be a unit cube, $K=(0,1)^{n}$, and let

$$
\begin{aligned}
H^{\#}= & \left\{v \in L_{2}\left(K ; \mathbf{R}^{n m}\right) \mid v=\nabla \bar{u}, \bar{u} \in H_{l o c}^{1}\left(\mathbf{R}^{n} ; \mathbf{R}^{m}\right), \bar{u} \text { is } K-\text { periodic }\right\}, \\
N^{\#}= & \left\{\eta \in L_{2}\left(K ; \mathbf{R}^{n m}\right) \mid \eta=\left(\eta_{1}, \ldots, \eta_{m}\right), \eta_{j}=\operatorname{div} \mathcal{U}_{j},\right. \\
& \mathcal{U}_{j} \in H_{l o c}^{1}\left(\mathbf{R}^{n} ; \mathbf{R}^{n \times n}\right) \text { is a skew-symmetric } \\
& \text { and } K \text { - periodic } n \times n \text { - matrix, } j=1, \ldots, m\} .
\end{aligned}
$$

We denote by $E\left(\nu^{\prime}, \mu^{\prime}\right)$ the set of all functions $F: \mathbf{R}^{n m} \rightarrow \mathbf{R}$ which satisfy the hypotheses $\mathbf{H 1}-\mathbf{H 3}$ with $\nu^{\prime}, \mu^{\prime}$ instead of $\nu, \mu$. Let

$$
\mathcal{A}=\left\{F_{\sigma} \in C\left(\mathbf{R}^{n m}\right) \mid F_{\sigma}(z)=\inf _{v \in H^{\#}} \int_{K} \sum_{s=1}^{N} \sigma_{s}(x) F_{s}(v(x)+z) d x, \sigma \in S\right\},
$$

let the function $Q \mathcal{F} \in C\left(\mathbf{R}^{n m} \times \mathbf{R}^{n m}\right)$ be defined as

$$
Q \mathcal{F}\left(z^{\prime}, z^{\prime \prime}\right)=\inf _{\sigma \in S} \inf _{v \in H^{\#}} \inf _{\eta \in N^{\#}} \int_{K} \sum_{s=1}^{N} \sigma_{s}(x)\left(F_{s}\left(v(x)+z^{\prime}\right)+F_{s}^{*}\left(\eta(x)+z^{\prime \prime}\right)\right) d x
$$

and let

$$
\hat{\mathcal{A}}=\left\{\hat{F} \in E\left(\nu, \frac{\mu^{2}}{\nu}\right) \mid \hat{F}\left(z^{\prime}\right)+\hat{F}^{*}\left(z^{\prime \prime}\right) \geq Q \mathcal{F}\left(z^{\prime}, z^{\prime \prime}\right) \forall z^{\prime}, z^{\prime \prime} \in \mathbf{R}^{n m}\right\} .
$$


We point out that the function $Q \mathcal{F}$ is the $A$-quasiconvex envelope, see I. Fonseca and S. Müller [1], of the function

$$
\mathcal{F}\left(z^{\prime}, z^{\prime \prime}\right)=\min _{S}\left(F_{s}\left(z^{\prime}\right)+F_{s}^{*}\left(z^{\prime \prime}\right)\right)
$$

for the operator $A=(\text { curl, div })^{m}$.

Our main result is the following.

Theorem 2.1. Let the hypotheses $\mathbf{H 1}$ - H3 hold. Then

i) $\mathcal{A} \subset \hat{\mathcal{A}}$;

ii) if $\hat{F} \in \hat{\mathcal{A}}$ then for every $z \in \mathbf{R}^{n m}$ there exists a sequence $\left\{\sigma^{k}\right\} \subset S$ (depending on the choice of $\hat{F}$ and $z$ ) such that

$$
F_{\sigma^{k}}^{\prime}(z) \underset{k \rightarrow \infty}{\longrightarrow} \hat{F}^{\prime}(z) \text { as } k \rightarrow \infty
$$

\section{PROOF OF THEOREM 2.1}

In this Section we shall give a brief sketch of the proof of Theorem 2.1.

First of all, the smoothness and growth properties of the functions $F_{s}$ and $F_{s}^{*}$ ensure that for every given $z^{\prime}, z^{\prime \prime} \in \mathbf{R}^{n m}, v \in H^{\#}, \eta \in N^{\#}$

$$
\begin{aligned}
\inf _{\sigma \in S} \int_{K} \sum_{s=1}^{N} \sigma_{s}(x)\left[F_{s}\left(v(x)+z^{\prime}\right)\right. & \left.+F_{s}^{*}\left(\eta(x)+z^{\prime \prime}\right)\right] d x \\
= & \int_{K} \min _{s}\left[F_{s}\left(v(x)+z^{\prime}\right)+F_{s}^{*}\left(\eta(x)+z^{\prime \prime}\right)\right] d x .
\end{aligned}
$$

This ensure that the function $Q \mathcal{F}$ defined by (2.1) is the (curl, div) ${ }^{m}$-quasiconvex envelope of the function $\mathcal{F}$ defined by (2.2).

Since the functions $F_{s}$ satisfy $\mathbf{H 1}-\mathbf{H 3}$ and the functions $F_{s}^{*}$ satisfy analogous hypotheses then almost exactly in the same way as in Miettinen and Raitums [2] it can be shown that the function $Q \mathcal{F}$ belongs to $C^{1}$. Further, from H1 $\mathbf{H} \mathbf{H}$ and results by Raitums [3] it easy follows that the set $\mathcal{A}$ belongs to $E\left(\nu, \mu^{2} / \nu\right)$.

If the function $F_{\sigma}$ is given as

$$
F_{\sigma}\left(z^{\prime}\right)=\inf _{v \in H \#} \int_{K} \sum_{s=1}^{N} \sigma_{s}(x) F_{s}\left(v(x)+z^{\prime}\right) d x
$$


then

$$
\begin{aligned}
F_{\sigma}^{*}\left(z^{\prime \prime}\right)= & \sup _{z^{\prime} \in \mathbf{R}^{n m}}\left[\left\langle z^{\prime}, z^{\prime \prime}\right\rangle-F_{\sigma}\left(z^{\prime}\right)\right] \\
& =\sup _{z^{\prime} \in \mathbf{R}^{n m}} \sup _{v \in H^{\#}}\left[-\int_{K} \sum_{s=1}^{N} \sigma_{s}(x) F_{s}\left(v(x)+z^{\prime}\right) d x+\left\langle z^{\prime}, z^{\prime \prime}\right\rangle\right] \\
& =\inf _{\eta \in N^{\#}} \int_{K} \sum_{s=1}^{N} \sigma_{s}(x) F_{s}^{*}\left(\eta(x)+z^{\prime \prime}\right) d x
\end{aligned}
$$

by virtue of the representation

$$
L_{2}\left(K ; \mathbf{R}^{n m}\right)=H^{\#} \oplus N^{\#} \oplus \mathbf{R}^{n m},
$$

see, for instance, Zhikov et al. [4]. This way, for every fixed $\sigma \in S$

$F_{\sigma}\left(z^{\prime}\right)+F_{\sigma}^{*}\left(z^{\prime \prime}\right)=\inf _{v \in H^{\#}} \inf _{\eta \in N^{\#}} \int_{K} \sum_{s=1}^{N} \sigma_{s}(x)\left(F_{s}\left(v(x)+z^{\prime}\right)+F_{s}^{*}\left(\eta(x)+z^{\prime \prime}\right)\right) d x$

i.e. the function $F_{\sigma}$ satisfies the inequality

$$
F_{\sigma}\left(z^{\prime}\right)+F_{\sigma}^{*}\left(z^{\prime \prime}\right) \geq Q \mathcal{F}\left(z^{\prime}, z^{\prime \prime}\right) \forall z^{\prime}, z^{\prime \prime} \in \mathbf{R}^{n m} .
$$

That gives the inclusion $\mathcal{A} \subset \hat{\mathcal{A}}$.

We point out here, that for every pair $\left(z^{\prime}, z^{\prime \prime}\right) \in \mathbf{R}^{n m} \times \mathbf{R}^{n m}$ there exists a sequence $\left\{\sigma^{k}\right\} \subset S$ such that

$$
F_{\sigma^{k}}\left(z^{\prime}\right)+F_{\sigma^{k}}^{*}\left(z^{\prime \prime}\right) \rightarrow Q \mathcal{F}\left(z^{\prime}, z^{\prime \prime}\right) \text { as } k \rightarrow \infty .
$$

That means that the estimate (3.2) is sharp.

By properties of conjugate functions we have that the equality

$$
\hat{F}\left(z^{\prime}\right)=z^{\prime \prime}
$$

for some $\hat{F}^{\prime} \in \hat{\mathcal{A}}$ and some pair $\left(z^{\prime}, z^{\prime \prime}\right) \in \mathbf{R}^{n m} \times \mathbf{R}^{n m}$ is equal to the relationship

$$
\hat{F}\left(z^{\prime}\right)+\hat{F}^{*}\left(z^{\prime \prime}\right)-\left\langle z^{\prime}, z^{\prime \prime}\right\rangle=0 .
$$

The same properties of conjugate functions and the definition (2.1) of $Q \mathcal{F}$ imply

$$
Q \mathcal{F}\left(\xi^{\prime}, \xi^{\prime \prime}\right) \geq\left\langle\xi^{\prime}, \xi^{\prime \prime}\right\rangle \forall \xi^{\prime}, \xi^{\prime \prime} \in \mathbf{R}^{n m} .
$$

We have used here the representation (3.1). 
Since $\hat{F} \subset \hat{\mathcal{A}}$ then the relationships (3.3), (3.4) imply

$$
Q \mathcal{F}\left(z^{\prime}, z^{\prime \prime}\right)=\left\langle z^{\prime}, z^{\prime \prime}\right\rangle
$$

Because, after taking the inner infimum in (2.1)

$$
Q \mathcal{F}\left(\xi^{\prime}, \xi^{\prime \prime}\right)=\inf _{\sigma \in S}\left[F_{\sigma}\left(\xi^{\prime}\right)+F_{\sigma}^{*}\left(\xi^{\prime \prime}\right)\right]
$$

then there exists a sequence $\left\{\sigma^{k}\right\} \subset S$ such that

$$
F_{\sigma^{k}}\left(z^{\prime}\right)+F_{\sigma^{k}}^{*}\left(z^{\prime \prime}\right)=\left\langle z^{\prime}, z^{\prime \prime}\right\rangle+\varepsilon_{k}, \varepsilon_{k} \rightarrow+0 \text { as } k \rightarrow \infty
$$

and, by duality,

$$
F_{\sigma^{k}}\left(z^{\prime}\right)+F_{\sigma^{k}}^{*}\left(F_{\sigma^{k}}^{\prime}\left(z^{\prime}\right)\right)=\left\langle z^{\prime}, F_{\sigma^{k}}^{\prime}\left(z^{\prime}\right)\right\rangle
$$

The set $\mathcal{A}$ belongs to $E\left(\nu, \mu^{2} / \nu\right)$, hence, all $F_{\sigma}^{*}$ belong to some class $E\left(\nu^{\prime}, \mu^{\prime}\right)$ and from (3.5) and (3.6) it follows

$$
\left|z^{\prime \prime}-F_{\sigma^{k}}^{\prime}\left(z^{\prime}\right)\right| \leq\left(\frac{2 \varepsilon_{k}}{\nu^{\prime}}\right)^{1 / 2}, k \geq 1
$$

But that means $F_{\sigma^{k}}^{\prime}\left(z^{\prime}\right) \rightarrow z^{\prime \prime}$ as $k \rightarrow \infty$. This way, the second statement of Theorem 2.1 is also proved.

\section{REFERENCES}

[1] I. Fonseca and S. Müller. A-quasiconvexity, lower semicontinuity, and Young measures. SIAM J.Math. Anal., 30, 1355 - 1390, 1999.

[2] M. Miettinen and U. Raitums. On $C^{1}$-regularity of functions that define G-closure. $Z$. Anal. Anwend., 20, 203 - 214, 2001.

[3] Raitums U. On the local representation of G-closure. Arch. Rational. Mech. Anal., 158, $213-234,2001$.

[4] Zhikov V.V., S.M. Kozlov and O.A. Oleinik. Homogenization of Differential Operators and Integral Functionals. Springer, Berlin Heidelberg New York, 1994.

\section{G-ribinių operatoriu globalioji charakteristika kvazitiesinèms po-} tencinèms elipsinèms sistemoms

U. Raitums

Straipsnyje nagrinejjama kvazitiesinių potencinių elipsinių sistemų šeima ir pasinaudojama, kad visi $G$-ribiniai operatoriai šiai šeimai gali būti charakterizuojami iškiliosios funkcijos $F$ gradiento (lokaliai erdvinių koordinačiu atžvilgiu) reikšmèmis. Parodyta, kad visos šios funkcijos $F$ tenkina nelygybę, išreikštą per funkcijas $F$ ir joms jungtines funkcijas. 